\title{
A case study of Turkish pre-service teachers of English in an international exchange program: ELF and WE perspectives
}

\author{
Işıl Günseli Kaçar a * \\ ${ }^{a}$ Department of Foreign Language Education, Middle East Technical University, Ankara, 06800, Ankara
}

Received 21 April 2020 | Received in revised form 23.03.2021 | Accepted 4 April 2021

\begin{abstract}
APA Citation:
Kaçar, I. G. (2021). A case study of Turkish pre-service teachers of English in an international exchange program: ELF and WE perspectives. Eurasian Journal of Applied Linguistics, 7(1), 435-457.
\end{abstract}

Doi: $10.32601 /$ ejal.911484

\begin{abstract}
Study/Teach abroad experiences, are shown to impact prospective teachers' beliefs and values, offering exposure to diverse educational systems and teaching philosophies. This qualitative exploratory case study aimed to investigate the impact of the Comenius language assistantship program on the sociolinguistic perspectives and meaning schemes of Turkish pre-service teachers of English, in different intercultural educational contexts in Europe between 2011 and 2014. It incorporated both English as a Lingua Franca (ELF) and World Englishes (WE) perspectives. The theoretical framework in the study is Mezirow's (1991) transformative learning theory. The data, collected via semi-structured interviews and reflective journals, were analyzed via content analysis. The findings indicated that although their social and educational backgrounds affected their interpretations of international teaching experiences, participants seemed to share an overarching sociolinguistic perspective. Changes emerged in four meaning schemes: inclusive pedagogical practices, teaching and learning English from the ELF- and WE-aware perspectives, creative and critical thinking activities, as well as intercultural awareness. The study underscored the necessity of integrating the following issues into pre-service language teacher education programs: intercultural awareness, competence, and communication, as well as linguistic and cultural diversity. The findings also emphasized the teacher educators' role as facilitators in terms of enhancing the transformative potential of the international teaching experiences.
\end{abstract}

(C) 2021 EJAL \& the Authors. Published by Eurasian Journal of Applied Linguistics (EJAL). This is an open-access article distributed under the terms and conditions of the Creative Commons Attribution license (CC BY-NC-ND) (http://creativecommons.org/licenses/by-nc-nd/4.0/).

Keywords: Study/teach abroad experiences; transformative learning ; pre-service teachers; meaning schemes; sociolinguistic perspective; intercultural awareness; World Englishes; English as a Lingua Franca

\section{Introduction}

\subsection{Study/teach abroad programs}

\footnotetext{
* Corresponding author.

E-mail address: isil@metu.edu.tr

$\underline{\text { http://dx.doi.org/10.32601/ejal.911484 }}$
} 
Study/Teach abroad, or international exchange programs, are defined as "a vehicle for integrating multiple disciplinary perspectives and weaving together existing commitments to explore diversity, build capacity for civic engagement, and prepare students to take responsibility for common global problems" (Hovland, 2009, p. 2). Comenius and Erasmus are two international exchange programs within the European Union's Lifelong Learning Program, which supports European education and training activities at school, college, university, or in the workplace and the community. The Comenius program provided teaching opportunities for pre-service teachers in multicultural school environments between 2001 and 2013 (British Council, 2010). It enabled participants to gain familiarity with new teaching methods, develop intercultural competence, raise their intercultural awareness, and improve their language skills. However, the Erasmus program was launched in 2000. It promotes the scientific knowledge dissemination, fosters the skills development in accordance with the changing needs and provides youth education reflecting European ideals (Dolasir \& Tuncel, 2004). Teacher/staff and student mobility, one of the main goals of the European Union Education policies, are regarded as integral components of the program (Pineda, Moreno, \& Belvis, 2008). Joint curriculum development and intensive teaching activities in these international learning/teaching programs were reported to contribute to the participants' professional development by raising their awareness of educational policies and inclusive teaching practices (Aydın, 2012).

\subsection{Benefits and challenges of study/teach abroad programs for EFL pre-service teachers}

Many researchers pointed out professional and personal affordances of study/teach abroad programs for pre-service teachers (e.g., Cushner, 2007). Regarding the personal gains of international teaching experiences, a multidimensional personal growth, in terms of enhanced self-confidence, problem-solving skills, leadership ability, adaptability, intercultural sensitivity, open-mindedness, and global-awareness, followed by reflexive thought processes, was reported (Aydın, 2012; Barkhuizen \& Feryok, 2006; Klein \& Wikan, 2019). Study/Teach abroad experiences are also indicated to influence participants' beliefs and values (Dooley, Dooley, \& Carranza, 2008).

Regarding professional affordances, study/teach abroad programs can provide opportunities for student teachers' professional development (Isabelli-García, Bown, Plews, \& Dewey, 2018). Such programs can promote pre-service teachers' intercultural competence (Çiftçi \& Karaman, 2019), empathy and tolerance, ways of dealing with domestic diversity (Cushner, 2007), awareness towards different educational philosophies, methodologies, and practices in diverse teaching contexts (Barkhuizen \& Feryok, 2006; Karaman \& Tochon, 2007; Trent, 2011). In fact, participants from teacher-centered educational backgrounds tend to be affected by the student-centered approaches in host countries (Aydın, 2012) and be motivated to change from an authority figure to a facilitator ( $\mathrm{Li} \&$ Edwards, 2013). Similarly, international teaching experiences play an important role in pre-service language teachers' identity (re)construction with gains in teaching repertoire, cultural knowledge, and language 
proficiency (Trent, 2011). Despite the aforementioned affordances of the study/teach abroad programs for pre-service teachers (Klein \& Wikan, 2019), some challenges were mentioned regarding the effectiveness of such programs (Vande Berg, Paige, \& Lou, 2012) such as the following: the short duration of the study/work abroad period constitutes one such concern (Klein \& Wikan 2019; Çiftçi \& Karaman, 2019), the lack of meaningful student engagement in study abroad experience, and lack of unfacilitated learning experiences during the international experience.

\subsection{ELF, WE, and intercultural awareness in teacher education}

To adapt to the changing and evolving landscape of pedagogy in the 21 st century, it is crucial to raise English language teachers' awareness towards diversity in multilingual and multicultural classrooms and the sociocultural and sociolinguistic realities of ELF (Bayyurt et al., 2019, p. 189) and to introduce them inclusive teaching practices to address the exponentially growing diverse learner population (Öztürk \& Aydın, 2019). 21st century teachers are expected to question "the suitability of one size fits all approaches in the teaching of languages used as a lingua franca like English" (Bayyurt, et al., 2019, pp. 188-189). (See also Biricik-Deniz, Özkan, \& Bayyurt, 2016). In this study, ELF "conceptualizes the multilingual and multicultural characteristics of communication in English with people from diverse linguistic and cultural backgrounds" (Bayyurt et al., 2019, p.188). In fact, intercultural awareness (ICA) facilitates international communication in ELF contexts in expanding circle settings (Baker, 2011). It is deemed necessary to acknowledge the pluralistic perspective associated with ELF-related communicative practices from an intercultural awareness perspective (Baker, 2011). ICA is related to the development of multilingual and multicultural competencies for effective intercultural communication (Canagarajah, 2007) in relation to ELF.

With an expansion in the multilingual zones in the globalized world, prospective teachers need to shift from the monolingual and normative orientation to an ELF-aware approach in English Language Teaching (ELT) (Bayyurt et al., 2019). To accomplish this shift, they need to gain familiarity with language variation and the language and identity relationship as well as developing critical reflection, effective communication, accommodation, adaptation, experiential and collaborative learning skills that play a pivotal role in ELF-aware teacher education (Bayyurt \& Sifakis, 2015a, 2015b; BiricikDeniz et al., 2016; Sifakis, 2007; Sifakis \& Bayyurt, 2018). In this study, the ELF-aware perspective refers to ELF research engagement and integration into learning environments via engagement in critical reflection, the classroom activity design and implementation, revealing one's own interpretation of the ELF construct (Sifakis \& Bayyurt, 2018).

Prospective English teachers of the 21st century are expected to develop awareness not only towards ELF but also towards WE, which can be defined as "all local English varieties regardless of which of Kachru's three circles (Kachru, 1985) they come from" (Jenkins, 2009, p. 200). The WE-aware approach in this study is 
characterized by an awareness towards "plurality" and a "plurithic perspective" (Vettorel, 2015), embracing the ownership of English by its users. Regarding the link between ELF and WE, Bayyurt and Dewey (2020) stated the use of English as a common contact language "among people from diverse linguistic and cultural backgrounds, with or without other shared languages that may be present in contexts of multilingual and multicultural societies" (p.371). In fact, Sifakis and Bayyurt (2015b) emphasized that non-native teachers in Expanding Circle contexts (like Turkey) are likely to embrace the integration of WE in their classroom "once they have understood and appreciated the validity and function of their own ELF varieties" (p.12). As Grazzi and Lopliore (2020) indicated, the co-existence of "conformity and creativity" in learners' linguistic performance" (Larsen-Freeman, 2016, p. 22) could be regarded as the meeting point of ELF and WE. Hence, this combination could be referred to as "a convergence point of the way the process of L2 learning unfolds in the English classroom, and the way the emergence of ELF takes place in a growingly multilingual and multicultural communicative contexts" (Grazzi \& Lopliore, 2020, p. 84).

\section{Literature Review}

\subsection{Theoretical framework: Mezirow's (1991) transformative learning framework}

Mezirow's (1991) theory of transformative (or transformational) learning constitutes the theoretical framework for this study. In accordance with the transformative learning theory, learning could be defined as "the process of using a prior interpretation to construe a new or revised interpretation of the meaning of one's experience in order to guide future action" (Mezirow, 1991, p. 42). It aims to explain how our cultural assumptions and presuppositions directly influence the meaning we derive from our experiences (Mezirow, 1991). The habits and expectations formed as a result of experiences in an adult's life could be categorized into two groups: meaning perspectives, or frames of reference, and meaning schemes (Mezirow, 1991).

Meaning perspectives constitute "the structure of assumptions and expectations through which we filter sense impressions" (Mezirow, 2000, p.16). A transformation in those perspectives results in transformative learning. Although our immediate beliefs and expectations (meaning schemes) can be subject to change, our general worldview (frame of reference) may remain intact (Sifakis, 2007). Mezirow (1997) believes that transformative learning is supported when learners are aware and can critically analyze their own and others' frames of reference, examine beliefs and experiences from different perspectives, and engage in discussion to support or reject current frames of reference.

Each meaning perspective is composed of several meaning schemes that are defined as "the particular knowledge, beliefs, value judgments, and feelings that become articulated in an interpretation" (Mezirow, 1991, p. 44). They refer to the points of view or actions that impact our assessments of or reactions towards different life experiences (Mezirow, 1991). In this study, the researcher sought to identify the pre-service 
teachers' overarching sociolinguistic meaning perspective and component meaning schemes that guided their interpretations of the international teaching experiences in different ELF educational settings.

The situation which leads to a profound change between individuals' previous understanding of the world and the new one is called a "disorienting dilemma" (Maciejewska, 2018, p. 352). Pre-service teachers in the study appeared to enrich their understanding of the world via interpreting new experiences, which tends to be disorienting, through critical reflections on their prior assumptions (See Mezirow, 2009). In cases where meaning schemes and perspectives fail to account for a particular life experience, new schemes and new perspectives could emerge which would be "more inclusive, discriminating, open, emotionally capable of change, and reflective" (Mezirow, 2000, p.7).

Given this study's focus on pre-service teachers' educational assumptions and beliefs in an international exchange program, the sociolinguistic meaning perspectives are of particular relevance. They are concerned with the impact of society and language on an individual's perceptions and understanding of reality and "are understood as habits of expectation assimilated primarily from one's culture and language" (Mezirow, 1991, p. 56). They emphasize the crucial role of culture, context, and language use in context, highlighting negotiated understanding (Mezirow, 1991). In Mezirow's (1991) terms, "culture can encourage or discourage transformative thought" (p. 3). In fact, the intercultural learning environments of the pre-service teachers in the Comenius program are likely to play an important role in promoting their intercultural awareness.

\subsection{Sifakis'(2004) transformative learning framework in ELF teacher education}

Sifakis' (2004) adapted Mezirow's (1991) transformative learning fra mework to ELF teacher education. It involves reflective practice and action research to enhance teaching efficiency and alter one's perspectives about "understanding and preparing for teaching ELF" (Sifakis, 2007, p. 364). As the study focused on the impact of the preservice teachers' international teaching experiences on their sociolinguistic meaning perspectives and meaning schemes from ELF- and WE-related perspectives, Sifakis' (2004) transformative learning framework is also relevant to the current study. It is necessary to adopt a 'transformative' approach in ELF teacher education as prospective and in-service teachers need to critically reflect on their established viewpoints and beliefs about language use, teaching and learning English as a Second/Foreign Language (ESOL) (Sifakis, 2004; 2009). The integration of ELF to ESOL is regarded as a demanding process as it entails reframing or reconceptualizing ELF-related core concepts such as "the role of the use of standard varieties of English in the foreign language classroom, the role of the native and non-native speakers in different communicative contexts, the issue of the ownership of English by its different users, the function of intelligibility in non-native speaker-non-native speaker (NNS-NNS) 
interactions, or the role of the non-native speaker teacher in an Expanding Circle context like Turkey" (Bayyurt \& Sifakis, 2015b, p. 128).

Sifakis' (2004) transformative framework for ELF-aware teacher education, involves the following steps: a) a critical examination of their assumptions, b) the exploration of the issue from different perspectives by adopting a new role, c) the design of an action plan, d) the acquisition of knowledge and skills to put the action plan into practice, e) enhancing self-confidence in the new role, f) the reintegration of the new role from a new perspective. Transformative learning in ELF education is claimed to empower participants as the users of the language as well as classroom practitioners (Sifakis, 2007).

Both rational and reflective discourse lie at the heart of transformative learning (Sifakis, 2007). In order for transformative learning to occur, individuals should engage in both. Rational discourse is the specialized use of dialogue for an understanding and assessment of the justification of an interpretation or belief (Mezirow, 2000). Reflective discourse, however, involves a critical assessment of assumptions, arguments, and the available evidence. During the transformative learning process, individuals need to exercise some degree of willingness to face their deeply ingrained beliefs and the cognitive maturity to "set aside bias, prejudice, and personal concerns . . . to arrive at a consensus" (Mezirow 2000, p.10).

\subsection{Studies on ELF-and WE-awareness in teacher education and study/teach abroad programs}

Although there has been a growing interest in research on the impact of the study/teach abroad programs on English as a foreign language (EFL) pre-service teachers' personal and professional development in the Turkish context over the last decades (See Aydın, 2012; Çiftçi \& Karaman, 2019), the impact of these programs on the Turkish EFL pre-service teachers' meaning perspectives and meaning schemes from the ELF and WE perspectives has not received due attention.

The transformative learning framework was integrated into a study on ELF-aware in-service teacher education by Bayyurt and Sifakis (2015b). The ELF-TED project by Bayyurt and Sifakis (2015b) aimed to raise Greek and Turkish EFL teachers' awareness towards their own beliefs regarding Standard English, native speakerism, the salience of intelligibility in interactions with non-native speakers, the EFL teachers' role as feedback providers. In line with the transformative framework (Mezirow, 1991), the participants were asked to reflect on their disorienting dilemmas triggered by the ELF-related reading materials. The findings revealed that the provision of reflection opportunities for EFL teachers' engagement in a re-orientation of their beliefs regarding "(a) their growing self-awareness as non-native speakers" was likely to boost their self-confidence as NNS communicators and as teachers (Sifakis \& Bayyurt, 2015b, p. 125). The study/teach abroad programs might be considered effective opportunities for EFL teachers' engagement in the aforementioned re-orientational and reflective processes that are likely to be transformative (See Sifakis, 2009). 
Regarding the studies on WE-awareness, Hamid and Baldauf (2013) found that teachers' perspectives play a crucial role in the treatment of learners' deviations from language standards. They argued for raising teachers' awareness towards the "plurality of Englishes, multiplicity of norms and the value of multilingualism" in this regard ( $p$. 490). In another study by Vettorel (2015), on the implications of WE, Italian pre-service teachers of English, reported a shift towards "plurality" and "a plurilithic perspective" and "fostering awareness of languages not as fixed entities but as changing living ones. shaped by use and users" (p. 240). In fact, the ELF- and WE-awareness is one meaning scheme that emerged in the study regarding the impact of the international teaching program on the pre-service teachers.

\subsection{The educational and cultural contexts of the host countries}

As the current study investigated the impact of the international teaching experiences in four host European countries (Spain, Italy, Sweden, and German) on the sociolinguistic meaning perspectives and meaning schemes of pre-service teachers in the Comenius program. This section presents the teaching contexts of these countries and to explore how these contexts contributed to these meaning perspectives and schemes.

\subsubsection{Spain}

Adopting English as a lingua franca, Spain promotes the European policies fostering multilingualism and the awareness of the need to learn foreign languages (Caraker, 2016). In fact, it leads to the development of content and language integrated learning (CLIL) in Europe, which refers to the teaching of non-language subjects either through two different languages, or through a single language which is described as 'foreign' according to the curriculum (Coyle, Hood, \& Marsh, 2010). CLIL has been promoted as a way of fostering multilingualism in both the monolingual and bilingual communities in Spain. Spanish teachers tend to extend the use of CLIL methodology to promote the students' communicative language ability development. (Caraker, 2016). In fact, the emphasis in the Spanish K-12 context on multilingualism and CLIL instruction as well as linguistic diversity via the adoption of the ELF perspective including the notion of English as a tool for communication contributed to the Turkish participants' transformation of their meaning perspectives and schemes. Also, the avoidance of a "norm-bound, approach to language and communication" (Sifakis, 2004, p.240) that does not "prioritise interlocutors' mutual comprehensibility and cultural identity" (Sifakis, 2004, p. 237) in the Spanish educational environments is likely to reframe the Turkish pre-service teachers' meaning perspectives and schemes.

\subsubsection{Italy}

The notion of ELF as a tool for global communication prevails in Italy. Since English became a compulsory school subject in 2011 (Bayyurt et al., 2019), trainee teachers in Italy have been introduced to ELF- and WE-related issues (Vettorel, 2015). They are 
prompted to shift from their monolithic perspective towards a plurithic one reflecting the dynamic and fluid nature of languages shaped by use and users as opposed to "fixed entities" (Vettorel, 2015). They are encouraged to question the concepts of standard language, nativeness, and language ownership, enhancing their awareness of different varieties of English as well as cultural and linguistic diversity of English users (Vettorel, 2015). Hence, the ELF- and WE-aware learning environment in Italy is conducive to the Turkish pre-service teachers' transformation of meaning perspectives and meaning schemes in the current study.

The participants' engagement in the planning and implementation of CLIL lessons during their international teaching experience in Italy may also reinforce their ELFaware perspective on teaching, leading them to a critical inquiry into their established beliefs and assumptions about teaching and learning English. In fact, the nationwide adoption of the CLIL approach by Italian English language teachers, particularly in primary and upper secondary schools since 2012 has helped them achieve meaningful interaction in or outside class and shift their focus away from learners' mistakes (Hüttner, 2018). Like in ELF-aware classrooms, the emphasis on effective and meaningful communication, contextualization, the avoidance of native speakeroriented pedagogies and the empowerment of learners to become competent users of English are the main features of CLIL classrooms (See Yalçın, Bayyurt, \& Alahdab, 2020). Hence CLIL practices in Italy could be considered "complimentary" to ELFaware ones (Yalçın et al., 2020, p. 8).

\subsubsection{Sweden}

English is regarded as a lingua franca in Sweden and a transcultural language as it is linked with Swedish values about globalisation, (Skolverket, 2011 as cited in Hult, 2017) The Swedish syllabus stresses the development of communication strategies (Skolvet, 2011 as cited in Hult, 2017). The translingual practices are also integrated into the Swedish education system as a pedagogical source in bilingual schools, emphasizing the use of linguistic and non-linguistic, semiotic, resources and the establishment of links between and across these sources (Jonnson, 2019).

The current syllabus emphasizes the adoption of a global perspective on teaching English in Sweden (Hult, 2017), decentring it from norm-dependent inner circle countries (Skoleverket, 2011 as cited in Hult, 2017). The inclusion of plurilingualism in the syllabus opens a potential opportunity for the establishment of a link between English and other languages in academia (Hult, 2017). English-medium classes with CLIL are growing in popularity in Sweden (Hult, 2017). Thus, the adoption of a global perspective towards teaching, the establishment of an ELF-aware learning environment, the avoidance of native speaker norms, and the incorporation of WErelated practices in the syllabus (e.g., pluriligualism) could be regarded as powerful stimuli to trigger the transformation of the Turkish pre-service teachers' meaning perspectives and meaning scheme in the study. The emphasis on effective communication in the Swedish context, where the teacher acts as a facilitator, might be considered awareness-raising for the pre-service teachers in the current study in 
terms of fostering learners' language development and their confident and successful use of English (See Bayyurt \& Dewey, 2020)

Entrepreneurship education, a specific, nationwide strategy adopted in the Swedish context romoting learner autonomy and empowerment. It prioritizes experiential learning opportunities such as project-based learning activities (European Commission, 2016; Van Lier, 2007). Critical thinking, problem-solving skills, and creative classroom activities for the learner empowerment are integrated in project-based learning in the Swedish education system (European Commission, 2012).

\subsubsection{Germany}

English plays a significant role as a lingua franca in Germany (Berns, 1995, p.7). Bilingual programs have been increasingly adopted to intensify foreign language education (Thaler, 2008 as cited in Ostinelli, 2009). Along with the growing popularity of English as a lingua franca, multilingualism and pluriculturalism are two popular current trends in Germany (Thaler, 2017). In this respect, the adoption of an ELFaware pedagogic perspective on ELT in German schools is likely to guide pre-service teachers in the study regarding the utilization of language resources and strategies to promote effective learner communication (See Bayyurt \& Dewey, 2020) for an extensive discussion on locating ELF in ELT). Thus, all these abovementioned factors are likely to have contributed to the study participants' transformation in their meaning perspectives and meaning schemes in Germany.

\section{Method}

\subsection{Research design}

The study is a qualitative exploratory case study of the prospective Turkish EFL teachers' sociolinguistic meaning perspectives and meaning schemes in diverse intercultural educational contexts in Europe from the ELF and WE perspectives in the Comenius language assistantship program. The case study research design was adopted as the researcher aimed to investigate the phenomenon under focus from the perspective of a small group of pre-service teachers in a tertiary educational setting (Yin, 2009).

\subsection{Participants}

The study involved 15 Turkish EFL pre-service teachers, six males and nine females, in the Comenius language assistantship program between 2011 and 2014. The participants were all junior students between 20 and 23 in an undergraduate program in ELT at an English-medium, urban state university in central Anatolia. They had a C1 level of proficiency in English. They were all chosen via random sampling. They worked as language teaching assistants and assisted teaching/learning activities at different K-12 schools in four host countries in Europe: Germany, Sweden, Italy, and Spain. Participants in Italy and Spain worked at primary schools while those in 
Germany were at secondary schools and those in Sweden were at high schools. Of the participants, four (one male, P4, and three females, P13, P14, and P9) went to Germany; four (two males, P2, P5, and two females, P1, and P3) to Sweden, four (two males, P8, P6, and two females, P12 and P11) to Italy and three (one male, P7 and two females P10, P15) to Spain. Prior to their involvement in the study, they completed the ELT methodology courses offered at the department. The duration of the international teaching experience for the participants was five months. Prior to their departure for the host countries, the university's Erasmus office held a meeting with the participants to inform them of the procedures to follow. They did not receive any training or guidance on how to facilitate their cultural adjustments or how to understand and function in a new and unfamiliar environment, either.

\subsection{Research questions}

The study addressed the following research questions:

1. In what ways did Turkish EFL pre-service teachers' international teaching experiences in the Comenius language assistantship program have an impact on their sociolinguistic meaning perspectives from the ELF and WE perspectives?

2. In what ways did Turkish pre-service teachers' international teaching experiences in the Comenius language assistantship program have an impact on their meaning schemes from the ELF and WE perspectives?

\subsection{Data collection}

The data were collected via semi-structured interviews prior to and following the sojourn period as well as reflective journals. Composed of open-ended questions, the interviews were conducted in the participants' native language, Turkish, to eliminate any potential language problems. Each interview lasted for one and a half hours. All the interviews were audio-recorded with the permission of the participants. The consent of the participants was obtained prior to the interviews and they were given the liberty to leave in case of discomfort. The interviews aimed to highlight the participants' expectations and assumptions through which they make sense of their international teaching experiences (i.e., their meaning perspectives) from ELF and WE perspectives as well as their particular knowledge, beliefs and feelings (their meaning schemes). The interview questions can be seen in Appendix A and Appendix B.

The pre-service teachers in the study were also asked to keep reflective journals in Turkish about their perceptions and feelings regarding their ELF- and WE-related professional and personal communication, pedagogical activities, and critical incidents, during their international teaching experience. every two weeks.

They were asked to reflect on their intercultural, personal, and professional insights during their international teaching experiences.

\subsection{Data analysis}


The qualitative data were analyzed via constant comparative analysis to identify the themes emerging from the pre- and post-sojourn data (Glaser \& Strauss, 2017). Qualitative coding procedures - open coding, axial coding, and selective coding- were used to analyze the emergent data. Several validation strategies were used to ensure reliability and validity: data triangulation, interrater reliability, member checking, and backtranslation (Creswell \& Miller, 2000).

Apart from the researcher, a departmental colleague, experienced in qualitative data analysis was involved in the data analysis for interrater reliability purposes. The researcher initially selected extracts from the interview transcripts to decide on the preliminary themes (Strauss \& Corbin, 1998). In line with the open coding methodology, selected segments of the transcripts were conceptually labeled (Strauss \& Corbin, 1990). Once the preliminary themes were determined, the researchers looked at the coding more analytically for categories that enabled comparison. Upon the completion of the initial analytical coding, broader categories emerged: one main meaning perspective and three meaning-scheme themes (axial coding) (Strauss \& Corbin, 1998). The researchers used the constant-comparative approach to confirm the emergent data (Lincoln \& Guba, 1985). Emergent categories were modified throughout the analysis process until they were refined to best represent the data. The interrater reliability was calculated to be $90 \%$ initially. Later on, both coders reached a consensus about the codes. Thick and rich descriptions were utilized to describe the participants' meaning perspectives and schemes and to reveal the role of such perspectives in forming the participants' assumptions and intercultural understanding (Lincoln \& Guba, 1985).

\section{Results and Discussion}

In this section the results are presented in relation to each research question in the study respectively. The results on the pre-service teachers' transformation of sociolinguistic meaning perspectives will be followed by those on the impact of the international teaching experience on their meaning schemes.

\subsection{The pre-service teachers' transformation of sociolinguistic meaning perspectives}

Regarding the first research question, the impact of the international teaching experiences on Turkish EFL pre-service teachers' sociolinguistic meaning perspectives, the results of the qualitative analysis revealed that despite their tendency to use their own social and educational backgrounds as benchmarks for judging the appropriateness and effectiveness of educational practices in different European K-12 schools, participants reflected on their insights into the educational practices of other cultures and settings. They appeared to keep their perspectives intact during the Comenius program. The current study indicated that the overarching sociolinguistic meaning perspective of the participants was that the social and cultural dimensions contribute significantly to what and how students learn (Lave \& Wenger, 1991). 
The findings corroborate those of Bayyurt and Sifakis' (2015b) ELF-TED project. Just like the in-service teachers in the project, the pre-service teachers in the current study indicated that their participation in the Comenius program fostered their appreciation of various ELF issues (Bayyurt \& Sifakis, 2015b). They reported that their program engagement helped them consider ways of personalising these issues in their own teaching contexts. Similar to the teachers in the ELF-TED project, the current study revealed that the participants' change process was gradual, arduous, and contingent upon personal and contextual constraints. It showed that besides the personality constrains such as the degree of openness to change, the context-related constraints were shown to impact the participants' self-perceptions of their professional roles as teachers and their wish to change their teaching style (Bayyurt \& Sifakis, 2015b). The pre-service teachers seemed to have adopted a reflective mindset during their internship experiences in different ELF educational settings. They appeared to have focused on what they might learn from multilingual and multicultural pedagogical practices in these settings, instead of adhering to their pre-existing pedagogical beliefs.

The current study also revealed that the pre-service teachers' pedagogical beliefs were influenced by contexts they lived in and their learning experiences in these contexts, confirming the multifaceted nature of the length of stay as a variable, (e.g., Bardovi-Harlig \& Bastos 2011). It indicated that while the normative EFL mindset in Turkey shaped their experiences of using English in different European countries, the pre-service teachers' socialization experiences in ELF communities reframed their understanding of English as a lingua franca in terms of the role it plays in their pedagogical perspectives (See Kaypak \& Ortaçtepe, 2014).

The pre-service teachers in the present study reported acknowledging the role of English as a lingua franca, as well as having a great deal of exposure to English through their intense interactions with their colleagues in English not only in the school contexts but also outside the school context (Kaypak \& Ortaçtepe, 2014). They also mentioned a high level of professional engagement in the preparation and implementation of ELF-aware classroom practices such as the adoption of CLIL and task-based methodologies and the use of authentic materials. They mentioned reshaping their professional identities in line with their growing awareness of and familiarity with the professional community they became part of (See also Çiftçi \& Karaman, 2019). They revisited their existing pedagogical beliefs in the light of their newly emerging pedagogical insights during the Comenius program. The following quote from Participant $1(\mathrm{P} 1)$ is a representative example:

During my international teaching experience in Sweden, I found it hard to reconcile with the concept of a teacher as a facilitator. Such a teacher profile was so different from the traditional authority figure in the Turkish context.

Observing her mentor who promoted the students' academic progress via autonomyinducing activities, regular feedback provision and tutoring led P1 to reflect on and reframe her pre-existing beliefs about teacher roles in her teacher-centered educational background, She added that having observed her mentor's facilitation for a while, she 
was also involved in facilitating students' learning process in Sweden, which gave her an opportunity to adopt her new teacher role and enhance her self confidence in this role (Sifakis, 2007). Her reflection on her prior beliefs about teacher roles and adoption of her new role as facilitator fostered her perspective adjustment. She reported embracing her role as a facilitator and a reflective practitioner after tutoring students. Similarly, being part of an international teaching program in Sweden with an emphasis on linguistic and cultural diversity (Hult, 2017) provided P5 with a professional learning opportunity to reflect on how to design and implement intercultural communication and accommodation strategies (McKay, 2010). During the semistructured interviews, he pointed out that his active engagement in the international teaching program resulted in his self-inquiry regarding his existing teaching perspectives. He remarked that he incorporated a global teaching perspective. His adoption of a pedagogy of English as an international language, which involves an emphasis on linguistic variation in English, during the Comenius program is consistent with the related literature (See Modiano, 2009).

\subsection{The impact of international teaching experience on the meaning schemes of pre- service teachers}

In relation to the second research question, the impact of pre-service teachers' international teaching experiences in the Comenius program on their emerging meaning schemes four meaning schemes emerged from the data analysis: inclusive pedagogical practices, teaching and learning English from the ELF and WE perspectives, the emphasis on critical thinking and creativity, and intercultural awareness.

\subsubsection{Meaning Scheme 1: Inclusive pedagogical practices}

The first meaning scheme in the study is related to inclusive pedagogical practices. Some participants pointed out that their mentors' professional stance in school contexts had an impact on their ideas on inclusive pedagogical practices. P3' comments are revealing in this respect:

I am amazed at the inclusive pedagogical practices in the Swedish context. In my family and at K-12 school different sexual orientations were not welcome.

P3 remarked that observing her mentor's tolerant and inclusive pedagogical attitude prompted her to launch a self-inquiry into her existing beliefs and assumptions about inclusive education (her engagement in reflective discourse). She remarked that critically analyzing her beliefs about the gender roles and inclusive education contributed to her professional empowerment as a novice teacher. She also reported designing an action plan based on her modified scheme (i.e., conducting a parentteacher meeting with the gay parents) contributed to her potentially transformative experience (Sifakis 2004). She added that her dialogic sharing with her mentor teacher who presented her with an inclusive pedagogical point of view (her engagement in rational discourse) promoted her to change her existing meaning scheme (Mezirow, 
2000; Sifakis, 2007;). Institutional culture in the host countries was found to be intertwined with the participants' perceptions of inclusive education in the semistructured interviews. To illustrate, P5 from Sweden emphasized the impact of the institutional culture in the host school on their meaning schemes regarding inclusive education.

Upon starting his international teaching experience, he remarked that he was informed of the core professional values such as mutual respect, tolerance, equity, and equality adopted by teachers and students in his host institution. His internalization of these professional values through his engagement in the institutional culture acted as a disorienting learning experience for him, shaping his emergent professional identity. He pointed out that being part of an institutional culture with inclusive values facilitated his inquiry-oriented reflective journey into his own transformative experience.

\subsubsection{Meaning scheme 2: Teaching and learning English from the ELF and WE perspectives}

The meaning scheme related to ELF and WE is the second theme regarding the meaning schemes in the study. The participants tended to problematize their existing meaning schemes to make sense of their international teaching experiences in different European countries from the ELF and WE perspectives. P12 indicated that during her international teaching experience in Italy, she described herself and her students as users of ELF, diverging from a native-speaker oriented approach to ELT (See Bayyurt \& Sifakis, 2015b). Just like in ELF-aware practices, she reported that in CLIL practices the focus was on using English and creating a motivating and an engaging environment for learners to start using English, to enable them to become confident users of English (Kordia, 2018; Sifakis \& Bayyurt, 2018). Also, the use of English as the medium of instruction in the CLIL lessons enabled her to focus on effective communication strategies (Yalçın et al., 2020). Just as Bayyurt and Sifakis (2015b) reported in their ELFTEd project, P12 pointed out that the emphasis on content in her CLIL classroom enabled her to use English for authentic purposes. (Yalçın et al., 2020). P12's engagement in ELF-aware pedagogy in CLIL lessons by presenting meaningful content in English and guiding her learners' use of language resources and strategies for effective communication prompted a change in her meaning scheme. She also viewed as invaluable her insights as to how the emphasis on effective communication strategies might foster learners' language development and their confident and successful use of English (Bayyurt \& Dewey, 2020). P7 from Spain highlighted that the alignment of the CLIL approach with the ELF-aware pedagogy promoted his self-confident stance as a non-native English teacher and empowered him professionally, which echoes the teachers in the ELFTed project (Bayyurt \& Sifakis, 2015b). Moreover, he indicated that his mentor's adoption of an ELF-aware perspective raised his awareness towards the use of English as a common language for intelligible communication as well as the linguistic and cultural diversity all around the globe (Sifakis \& Bayyurt, 2018; Vettorel, 2015). 
During the semi-structured interviews, both P7 and P12 pointed out that their mentors' awareness towards the "plurality of Englishes, multiplicity of norms and the value of multilingualism" (Hamid \& Baldauf, 2013, p. 490) also had an impact on the normative native-speaker oriented mindset to teaching English which is deeply entrenched in their educational background. Referring to the link between ELF and WE, they saw the need for the accommodation of the local English variety to render it more intelligible and appropriate for their interlocutors in a particular ELF communication, irrespective of which circle one belongs to from an ELF perspective (Jenkins, 2009). They also reflected the change in their ELF- and WE-related meaning scheme during the interviews when they pointed out the need to enable pre-service teachers to become "ELF-aware critical pedagogues" (Biricik-Deniz et al., 2016, p.145) and WE-aware practitioners who recognize "the linguistic creativity and diversity in multilingual situations across cultures" (Kachru, 1985, as cited in Biricik-Deniz et al., 2016, p.145).

Becoming aware of how ELF communication can be viewed as a translanguaging act served as a wake-up call for $\mathrm{P} 4$ from Sweden who held monolithic norm-oriented beliefs from her previous educational background. She pointed out that "observing translanguaging as an instructional strategy to make links for learners between the social, cultural, community, and linguistic domains of their lives" (Creese \& Blackledge, 2010, p. 112) prompted her to reframe her perspectives on the effective instructional strategies. She revealed that observing her mentor's translingual practices such as allowing students to interchange between their linguistic resources and non-linguistic resources in intercultural communication acted as a game-changer for her (Hult, 2017).

The international teaching experience in the Comenius program gave participants an opportunity to comprehend ELF communication. They revealed that the most significant insight they gained through the experience was the importance of the effective negotiation of meaning (i.e., the process of adaption and accommodation) between interlocutors in an effective intercultural interaction (Sifakis, 2019). The point where participants realized that effective intercultural interaction does not depend on complying with native speaker norms was a crucial point for their transformative learning process (e.g., Mauranen, 2010.)

P3 from Sweden remarked in her reflective journals that she learnt how to align her classroom practices with ELF-aware pedagogy during her international teaching experiences. She reported seeing the incompatibility between her newly discovered ELF perspective on communication and her previous SLA perspective, where ELF communication used to be perceived as a "relatively deficient concept" for L2 users of English (See Yalçın, et al. 2019, p.8). The educational context in Sweden appears to be conducive to Dewey's (2012) conceptualization of a post-normative model of learner multicompetence, prioritizing the process of communication likely to embrace multilingualism. 


\subsubsection{Meaning scheme 3: Creative and critical thinking activities}

Pre-service teachers' professional development through their engagement in critical thinking and creative activity design and implementation is the third meaning scheme in the study. The participants from Italy reported becoming more creative and critical thinkers as a result of their international teaching experience (Deveci, 2014). In fact, P8 from Italy stated that being involved in the creative classroom activity design in English lessons using CLIL methodology enhanced his creativity, making him feel motivated by pushing the limits of his imagination, thereby assisting his transformative learning experience. Regarding the impact of creativity in CLIL lessons on learners' linguistic performance in the Italian ELF context, P8 pointed out that Italian young learners' linguistic productions involved both creativity and conformity, which can be considered the meeting point of ELF and WE, "in a growingly multilingual and multicultural communicative contexts" (Grazzi \& Lopliore, 2020, p. 84).

The experiences of the participants from Sweden were also along similar lines. For instance, P12 and P6 pointed out the emphasis on experiential learning opportunities (e.g., project-based activities) as part of the entrepreneurial teaching pedagogy promoted creative and critical thinking skills, learner autonomy in the Swedish education system (European Commission, 2016; Van Lier, 2007). When they perceived their role as the change agent and the facilitator, pre-service teachers felt empowered professionally, which fueled their transformative learning experience. They indicated that engaging students in project work contributed to the latter's sense of social responsibility, sharpening their problem-solving skills and critical thinking abilities. In addition, P1 and P3 reported gaining new insights into the benefits of integrating creative language use into English classes in terms of preparing language learners for the "diversity and unpredictability of real-life communication outside the school walls" (Illes \& Akcan, 2017, p.10).

\subsubsection{Meaning scheme 4: Intercultural awareness}

The final meaning scheme in the study is related to intercultural awareness. The preservice teachers in the study pointed out a change in their cultural consciousness. They indicated that their involvement in the international teaching program had the impact of raising their level of intercultural consciousness. The following quote is an effective representation of $\mathrm{P} 13$ ' perceptions in this respect:

I learned more about how to relate to people from different cultures and backgrounds through my international teaching experience in Germany. We can't assume people in other cultures do things the same way we do.

As the aforementioned quote reflects, P13 from Germany reported gaining insights into local cultures and embracing an open-minded and reflective perspective geared to improving his intercultural communication skills (Çiftçi \& Karaman, 2019). In lieu of adopting a judgmental mindset towards intercultural differences characterized by taboos and stereotypes and perceiving intercultural differences as a threat, he chose to respect and celebrate diversity. 
All the participants in the study frequently pointed out the importance of moving out of their comfort zones to launch a self-inquiry into their existing assumptions about the intercultural diversity (Mezirow, 2009). They placed an emphasis on cultivating a reflective mindset to develop new perspectives into their learning experiences or reframe their existing assumptions about other cultures. Regarding his intercultural insights during his international teaching experience in Sweden, P2 wrote about the established Fika culture in his reflective journal. The following quote is concerned with the positive impact of this culture on his identity construction:

The Fika culture is an important part of the institutional culture at my school in Sweden. It made me feel I was already a staff member from the very beginning. It is quite rare to find such a friendly working environment in Turkey.

In the quote above, $\mathrm{P} 2$ emphasized the important role the Fika culture played in his identity construction during his international teaching experience in several ways. Apart from his gains in cultural knowledge (Trent, 2011), the Fika gatherings facilitated his entry to the professional community at school. They helped him gain a sense of peer belonging and institutional acceptance and establish his professional network at school. These findings were in line with Plews, Breckenridge and Cabre (2010), emphasizing the vital role the recognition of participant teachers' identities play in their identity construction during the international teaching experiences. P2 reported that student teachers in Turkey do not tend to be readily admitted to the professional community during their practicum period as they are not usually acknowledged to be proper teachers. He compared the community of teachers in his home country with the one in the host country, which gave him an opportunity to gain familiarity with different institutional cultures (Barkhuizen \& Feryok, 2006).

P10 and P8 from Italy also stated that their engagement in the CLIL approach enhanced their intercultural awareness. They indicated that being involved the preparation and implementation of CLIL activities in the international exchange program raised their awareness towards different uses of English. They emphasized that the adoption of the CLIL approach contributed to their linguistic and cultural competence (Yalçın et al., 2020).

Although participants in the study tended to advance in their transformative learning experiences, most of them were not likely to finalize the transformative process, which required "the reintegration of the new perspective into their life and practice" (Sifakis, 2007, p. 363). The relatively short duration of the program might pose an obstacle for their integration of new meaning schemes into their own teaching contexts.

The findings of the current study were also consistent with those of Bayyurt and Sifakis (2015b), concluding that transformation was observed in the teachers' own perceptions as non-native speakers of English (See Bayyurt \& Sifakis, 2015b). The preservice teachers in the study underwent a mentality shift from feeling " 'subordinate' to a 'superior' native speaker to... a speaker feeling equal to, if not better equipped than, native speakers to deal with the needs of a communicative situation involving other 
non-native speakers" (See Bayyurt \& Sifakis, 2015b, p.128). Their realization of the implications of the function of English as a lingua franca was the point when the transformation started (Also see Kaypak \& Ortaçtepe, 2014)

\section{Conclusion}

The study provided insights regarding the changes in the sociolinguistic perspectives and meaning schemes of the Turkish EFL pre-service teachers in the Comenius program. No significant changes were found in the overarching sociolinguistic perspective of pre-service teachers, although their previous socialization had some impact on their general framework of reference. The prospective teachers in the international teaching program reported some modifications in their meaning schemes depending on personal and contextual constraints (Sifakis, 2007). The study concluded that the exchange program can be regarded as a 'potentially transformative' process (Sifakis \& Bayyurt, 2018, p. 460) that is "slow and painstaking" for the pre-service teachers' ELF-aware perspectives (Bayyurt \& Sifakis, 2015b, p.130) and WE-aware perspectives (See Vettorel, 2015). Although participants were exposed to normative pedagogies in their educational background, their personality characteristics such as their receptivity to different perspectives and their communicative, reflective, and critical attitudes were found conducive to their shift towards the ELF-aware and WEaware perspectives (Bayyurt \& Sifakis, 2015b).

Although the participants critically reflected on their previous professional and intercultural teaching/learning experiences in the program and developed new insights on the integration of these experiences into their classroom practices, it is not quite clear whether they have been able to fully integrate the self-reported changes into their professional and personal repertoires. Considering the limited duration of the international teaching program, the limited teaching practice and intercultural exchange opportunities in the program, a fully transformative learning experience may not be likely (Deveci, 2014; King, 2005; Ortaçtepe \& Kaypak, 2014). Alternatively, participants' 'transformative experiences' may be called as personally moving but may not necessarily represent a shift in their frame of reference (Vande Berg, et al., 2012). The change may also be temporary or situational (Klein \& Wikan, 2019). Alternatively, although the participants may assert that they have become more tolerant and openminded at one level, at another level, they may have reinforced their ethnocentric attitudes (Klein \& Wikan, 2019).

Regarding the classroom implications, constituting the key to transformative learning (Mezirow, 1997), critical reflection should be a built-in feature of the international teaching programs from the pre-departure to the post-sojourn period (Klein \& Wikan, 2019). Pre-service teachers might also be offered an intercultural development course that could cater for their communication and adjustment needs in the host country (Kural, 2020). The teacher educators also need to promote pre-service teachers to develop a growth mindset characterized by an open-minded attitude to construct personalized meanings. The pre-service teacher education programs are also 
likely to benefit from the integration of ELF- and WE-integrated courses such as World Englishes and Culture and Language and Culture to enhance the intercultural/multicultural competence of pre-service teachers. The integration of a virtual exchange component into the physical mobility might also be considered a beneficial opportunity for the exchange program participants to develop intercultural communication and collaborative learning skills (Helm \& Van der Velden, 2019).

Despite having a limited sample size, the study might highlight some guidelines for other EFL pre-service teacher educators in similar contexts striving to enhance the transformative potential of the exchange programs for prospective participants and to assist them to develop strategies to meet potential program challenges. Regarding further research studies, longitudinal qualitative research is recommended with different pre-service teacher profiles in different educational settings, (Karaman \& Çiftçi, 2019; Klein \& Wikan, 2019). Of equal importance is quantitative, mixed methods, or comparative research that may involve a larger population size. Follow-up studies might also be conducted to focus on the long-term effects of exchange programs on participants' teaching practices in their local contexts.

\section{Acknowledgement}

I would like to thank all the participant preservice teachers at Middle East Technical University, the Department of Foreign Language Education (FLE) for their valuable contributions to the study. I would also like to thank our Erasmus coordinator at the department of FLE and the university's Erasmus office for their assistance in the participant recruitment for the research study. I would like to extend my appreciation to Prof, Dr. Yasemin Bayyurt and Prof. Dr. Eva Illes for their clear guidance, invaluable comments and suggestions and as well as Prof. Dr. Ece Zehir Topkaya for her facilitation throughout the publication process.

\section{The Research and Publication Ethics Statement}

The study did not require to get a permission from the ethics committee.

\section{The Conflict of Interest Statement}

In line with the statement of Committee on Publication Ethics (COPE), I hereby declare that I had no conflicting interests regarding any parties of this study. I did not receive any funding for the study.

\section{References}

Aydın, S. (2012). "I am not the same after my ERASMUS": A qualitative research. The Qualitative Report, 17(28), 1-23.

Baker, W. (2011). Intercultural awareness: Modelling and understanding of cultures in intercultural communication through English as a lingua franca. Language and Intercultural Communication, 11(3), 197-214. 
Bardovi-Harlig, K. \& Bastos, M. T. (2011). Proficiency, length of stay, and intensity of interaction and the acquisition of conventional expressions in L2 pragmatics. Intercultural Pragmatics, $8,347-384$.

Barkhuizen, G., \& Feryok, A. (2006). Pre-service teachers' perceptions of a short-term international experience program. Asia-Pacific Journal of Teacher Education, 34(1), 115-134.

Bayyurt, Y. \& Dewey, M. (2020). Locating ELF in ELT. ELT Journal, 74(4), 369-376.

Bayyurt, Y., Kurt, Y., Öztekin, E., Guerra, L., Cavalheiro, L., \& Pereira, R. (2019). English language teachers' awareness of English as a lingua franca in multilingual and multicultural contexts. Eurasian Journal of Applied Linguistics, 5(2), 185-202.

Bayyurt, Y., \& Sifakis, N. C. (2015a). Developing an ELF-aware pedagogy: Insights from a selfeducation programme. New frontiers in teaching and learning English, 55-76.

Bayyurt, Y., \& Sifakis, N. C. (2015b). ELF-aware in-service teacher education: A transformative perspective. In H. Bowles, \& A. Cogo (Eds.), International perspectives on English as a lingua franca (pp. 117-135). Basingstoke, UK: Palgrave Macmillan.

Berns, M. (1995). English in Europe: Whose language, which culture. International Journal of Applied Linguistics, 5(1), 21-32.

Biricik-Deniz, E., Özkan, Y., \& Bayyurt, Y. (2016). English as a lingua franca: Reflections on ELF-related issues by pre-service English language teachers in Turkey. The Reading Matrix, 16(2), 144-161.

British Council (2010). 2010 Activity report: Comenius and Erasmus. Retrieved from https://www.erasmusplus.org.uk/file/425/download.

Canagarajah, A. S. (2007). Lingua franca English, multilingual communities, and language acquisition. The Modern Language Journal, 91(5), 923-939.

Caraker, R. (2016). Spain and the context of English language education. Research Bulletin, 92, 23-35.

Coyle, D., Hood, D., \& Marsh, D. (2010). Content and language integrated learning. Cambridge University Press.

Creese, A., \& Blackledge, A. (2010). Translanguaging in the bilingual classroom: A pedagogy for learning and teaching? The Modern Language Journal, 94(1), 103-115.

Creswell. J. W., \& Miller, D. L. (2000). Determining validity in qualitative inquiry. Theory into Practice, 39, 124-130.

Cushner, K. (2007). The role of experience in the making of internationally-minded teachers. Teacher Education Quarterly, 34(1), 27-39.

Çiftçi, E., \& Karaman, A. (2019). Short-term international experiences in language teacher education: A qualitative meta-synthesis. Australian Journal of Teacher Education, 44(1), 93119.

Deveci, T. (2014). The transformative learning experiences of learners of English as a foreign language at a university preparatory program: Transformative dialogues: Teaching and Learning Journal, 7(39), 1-19.

Dewey, M. (2012). 'Towards a post-normative approach: Learning the pedagogy of ELF. Journal of English as a Lingua Franca 1, 147-70.

Dolasir, S., \& Tuncel, F. (2004, May). Evaluating the Turkish higher education law and proposals in the light of Erasmus goals. Paper presented at the First International Congress on University Education, Istanbul, Turkey.

Dooley, K. E., Dooley, L. M., \& Carranza, G. (2008). Beliefs, barriers, and benefits of a faculty abroad experience in Mexico. Journal of International Agricultural and Extension Education, 15(3), 29-38. 
European Commission (2012). Rethinking education: Investing in skills for better socio-economic outcomes. Strasbourg: Consortium for Entrepreneurship Education.

European Commission /EACEA/Eurydice. (2016). Entrepreneurship education at schools in Europe. Eurydice report. Luxembourg: Publications Office of the European Union.

Glaser, B., \& Strauss, A. (1967). The discovery of grounded theory. Chicago: Aldine.

Grazzi, E., \& Lopliore, L. (2020). ELF awareness for teacher education in Italy: Attitudes and actions. Estudos, 65, 69-89.

Hamid, M. O., \& Baldauf, R. B. (2013). Second language errors and features of world Englishes. World Englishes, 32(4), 476-494.

Helm, F., \& van der Velden, B. (2020). Erasmus+ Virtual Exchange Impact Report 2019. https://op.europa.eu/en/publication-detail/-/publication/a6996e63-a9d2-11e9-9d0101aa75ed71a1.

Hovland, K. (2009). Global learning: What is it? Who is responsible for it? Peer Review, Fall, 4-7.

Hult, F.M. (2017). More than a lingua franca: Functions of English in a globalised educational language policy, Language, Culture and Curriculum, 30(3), 265-282.

Hüttner, J. (2018). ELF and content and language integrated learning. In J. Jenkins, W. Baker, \& M. Dewey (Eds.). The Routledge Handbook of English as a Lingua Franca (pp. 481-493). New York: Routledge.

Illes, E., \& Akcan, S. (2017). Bringing real-life language use into EFL classrooms. ELT Journal, 71(1), 3-12, 2017.

Isabelli-García, C., Bown, J., Plews, J. L., \& Dewey, D. P. (2018). Language learning and study abroad. Language Teaching, 51(4), 439-484.

Jenkins, J. (2009). English as a lingua franca: Interpretations and attitudes. World Englishes, 28(2), 200-207.

Kachru, B. (1985) Standards, codification, and sociolinguistic realism: The English language in the Outer Circle. In R. Quirk \& H. G. Widdowson (Eds.), English in the world: Teaching and learning the language and literatures (pp. 11-30). Cambridge: Cambridge University Press.

Karaman, A. C., \& Tochon, F. V. (2007). International student teaching in world language education: Critical criteria for global teacherhood. Critical Inquiry in Language Studies, 4(23), 237-264.

Kaypak, E., \& Ortaçtepe, D. (2014). Language learner beliefs and study abroad: A study on English as a lingua franca (ELF). System, 42, 355-367.

King, K. P. (2005). Bringing transformative learning to life. Krieger.

Klein, J. \& Wikan, G. (2019). Teacher education and international practice programmes: Reflections on transformative learning and global citizenship. Teaching and Teacher Education, 79, 93-10.

Kordia, S. (2018). ELF-aware teaching in practice: a teacher's perspective. In N. C. Sifakis \& N. Tsantila (Eds.). English as a Lingua Franca for EFL Contexts (pp. 53-71). Bristol: Multilingual Matters.

Kural, F. (2020). Long term effects of intercultural competence development training for study abroad adjustment and global communication. Journal of Language and Linguistic Studies, 16(2), 948-95.

Larsen-Freeman, D. (2016). Classroom-oriented research from a complex systems perspective. Studies in Second Language Learning and Teaching Department of English Studies, 6(3), 377-393.

Lave, J., \& Wenger, E. (1991). Situated learning: Legitimate peripheral participation in communities of practice. New York: Cambridge University Press. 
Li, D., \& Edwards, V. (2013). The impact of overseas training on curriculum innovation and change in English language education in Western China. Language Teaching Research, 17, 390-408.

Lincoln, Y. S., \& Guba, E. G. (1985). Naturalistic inquiry. Newbury Park, CA: Sage.

Maciejewska, M. (2018). Opportunities of transformative student learning - The case of the Erasmus+ programme. Proceedings of the International Scientific Conference: Society. Integration. Education (pp. 350-360). Rēzekne, Latvija: Rēzeknes Tehnoloğiju akadēmija.

Mauranen, A. (2010). Discourse reflexivity- discourse universal?: The case of ELF. Nordic Journal of English Studies, 9(2), 13-40.

McKay, S. L. (2010). English as an international language. In N. H. Hornberger \& S. L. McKay (Eds.), Sociolinguistics and language education (pp. 89-115). Bristol: Multilingual Matters.

Mezirow J. (1991). Transformative dimensions of adult learning. San Francisco: Jossey-Bass.

Mezirow, J. (1997). Transformative learning: Theory to practice. New Directions for Adult and Continuing Education, 74, 5-12.

Mezirow, J. (2000). Learning to think like an adult: Core concepts of transformation theory. In J. Mezirow \& Associates (Eds.), Learning as transformation: Critical perspectives on a theory in progress (pp. 3-34). San Francisco: Jossey-Bass.

Mezirow, J. (2009). An overview on transformative learning. In K. Illeri (Ed.), Contemporary theories of learning: Learning theorists in their own words (pp. 7-20). London and New York: Routledge.

Modiano, M. (2009). Language learning in the multicultural classroom: English in a European and global perspective. Lund: Studentlitteratur.

Ostinelli, G. (2009). Teacher education in Italy, Germany, England, Sweden and Finland. European Journal of Education, 44(2), 291-308.

Öztürk, G., \& Aydın, B. (2019). English language teacher education in Turkey: Why do we fail and what policy reforms are needed? Anadolu Journal of Educational Sciences International, 9(1), 181-213.

Pineda, P., Moreno, V., \& Belvis, E. (2008). The mobility of university students in Europe and Spain. European Educational Research Journal, 7(3), 273-288.

Plews, J. L., Breckenridge, Y., \& Cambre, M.C. (2010). Mexican English teachers' experiences of international professional development in Canada: A narrative analysis. Electronic Journal of Foreign Language Teaching, 7(1), 5- 20.

Sifakis, N. C. (2004). Teaching EIL-Teaching intercultural or international English: What teachers should know. System, 32(3), 237-250.

Sifakis, N. C. (2007). The education of teachers of English as a lingua franca: A transformative perspective. International Journal of Applied Linguistics, 17(3), 355-374.

Sifakis, N. C. (2009). Challenges in teaching ELF in the periphery: The Greek context. ELT Journal, 63(3), 230-237.

Sifakis, N. C. (2019). ELF awareness in English Language Teaching: principles and processes. Applied Linguistics, 40(2), 288-306.

Sifakis, N. C. \& Bayyurt, Y. (2015). Insights from ELF and WE in teacher training in Greece and Turkey. World Englishes, 10, 471-484.

Sifakis, N., \& Bayyurt, Y. (2018). ELF-aware teaching, learning and teacher development. In J. Jenkins, W. Baker, \& M. Dewey (Eds.), Handbook of English as a lingua franca (pp. 456467). London and New York: Routledge.

Strauss A. \& Corbin, J. (1998). Basics of qualitative research: Techniques and procedures for developing grounded theory. Thousand Oaks, CA: Sage Publications, Inc. 
Thaler, E. (2017). English and foreign language teaching in German gymnasium. Training Language and Culture, 1(3), 72-85.

Trent, J. (2011). Learning, teaching, and constructing identities: ESL pre-service teacher experiences during a short-term international experience program. Asia Pacific Journal of Education, 31(2), 177-194.

Van Lier, L. (2007) Action-based teaching, autonomy and identity. Innovation in Language Learning and Teaching, 1(1), 46-65.

Vande Berg, M., Paige, R.M., \& Lou, K.H. (2012). Student learning abroad: What our students are learning what they're not, and what we can do about it. Sterling, VA: Stylus.

Vettorel, P. (2015). World Englishes and English as a lingua franca: Implications for teacher education and ELT. Iperstoria-Testi Letterature Linguaggi Rivista Semestrale, 6, 229-244.

Yalçın, Ş., Bayyurt, Y., \& Alahdab, B.R. (2020). Triggering effect of CLIL practice on English as a lingua franca awareness. ELT Journal, 74(4), 387-397.

Yin, R. K. (2009). Case study research design and methods (4th ed.). Sage Publications.

\section{Appendix A. Semi-structured Interview Questions Before the Sojourn}

1. Please describe your teaching philosophy. What are your beliefs about effective language teaching and learning?

2. In what ways do you think the Comenius program is likely to contribute to your pedagogical practices and professional development?

3. In what ways do you think the Comenius program is likely to contribute to your personal development as a prospective teacher?

4. What might be the challenges you are likely to face in the Comenius program?

\section{Appendix B. Semi-structured Interview Questions After the Sojourn}

1. In what ways did your participation in the Comenius program contribute to your pedagogical practices and professional development? Please explain by providing anecdotal evidence concerning your professional learning experience on the program.

2. In what ways did your participation in the Comenius program contribute to your intercultural development? Please explain by providing anecdotal evidence regarding your intercultural learning experiences on the program.

3. In what ways did the Comenius program contribute to your personal development. Please explain by providing anecdotal evidence regarding your personal learning experiences on the program.

\section{Copyrights}

Copyright for this article is retained by the author(s), with first publication rights granted to the Journal.

This is an open-access article distributed under the terms and conditions of the Creative Commons Attribution license (CC BY-NC-ND) (http://creativecommons.org/licenses/by-nc-nd/4.0/). 